\title{
Análise de estruturas geopolíticas e de tendências de aumento da competição interestatal internacional: contribuições para a prospecção de cenários de ameaças à Soberania Brasileira sobre o Pré-Sal
}

\author{
Geopolitical structures analysis and trends \\ of international competition increasing: \\ contributions for prospecting scenarios \\ of threats to Brazilian sovereignty on Pre-Salt
}

Rev. Bra. Est. Def. v. 3, nº 2, jul./dez. 2016, p. 139-176

ISSN 2358-3932

\section{LUCAS KERR OLIVEIRA SUELLEN MAYARA PERES OLIVEIRA BESNA GISSEL RODRIGUEZ YACOVENCO BRUNO MAGNO PATRÍCIA DE FREITAS}

\section{INTRODUÇÃO}

O objetivo deste artigo é analisar os principais desafios para o Brasil, efetivamente, manter e exercer a soberania sobre as ricas reservas petrolíferas do pré-sal. Para isso são analisadas as condições geopolíticas e es-

Os autores agradecem as críticas e sugestões pertinentes realizadas em debates com os colegas do Instituto Sul-Americano de Política e Estratégia, ISAPE, do Centro de Estudos Internacionais sobre Governo, CEGOV (UFRGS) e no Núcleo de Estudos Estratégicos, Geopolítica e Integração, NEEGI (UNILA), destacando que responsabilidade por erros ou equívocos é exclusivamente dos autores. Versões anteriores, parciais, deste texto foram apresentadas separadamente no Encontro Nacional da ABRI em 2015, no Encontro Regional da ABED em 2015 e no Encontro Nacional da ABED de 2016. Lucas Kerr Oliveira - Professor Adjunto da Universidade Federal da Integração Latino-Americana (UNILA).E-mail: lucas.oliveira@unila.edu.br

Suellen Mayara Peres Oliveira - Professora Adjunta da Universidade Federal da Integração LatinoAmericana (UNILA). E-mail: <suellen.oliveira@unila.edu.br.

Besna Gissel Rodriguez Yacovenco - Mestranda e bolsista do Programa de Pós-Graduação em Integração Contemporânea na América Latina (PPGICAL-UNILA). E-mail: <besna.yacovenco@aluno.unila.edu.br.

Bruno Magno - Mestrando e bolsista CNPq no Programa de Pós-Graduação em Estudos Estratégicos Internacionais (PPGEEI-UFRGS). Pesquisador colaborador do Instituto Sul-Americano de Política e Estratégia (ISAPE). E-mail: <brunomgn@gmail.com.

Patrícia de Freitas - Mestranda e bolsista do Programa de Pós-Graduação em Integração Contemporânea na América Latina (PPGICAL-UNILA). E-mail: <patricia.ri.unila@gmail.com. 
tratégicas de longo prazo que importam para a construção de cenários de ameaças diretas à soberania brasileira do pré-sal. Deste modo, procurou-se construir o "grande cenário de fundo", em que se poderia identificar as forças motrizes que impulsionam, atualmente, e tendem a continuar impulsionando, as grandes transformações do sistema internacional nas próximas décadas. A partir da identificação destas forças, é possível notar que a principal tendência para o sistema consiste no aprofundamento ou acirramento da competição internacional interestatal entre as grandes potências (Arrighi, 1996; Mearsheimer, 2001; Pinheiro Guimarães, 2006; Vizentini \& Wiesebron 2006; Fiori, 2009). Esta é uma variável bastante relevante para a discussão sobre a formulação de uma grande estratégia brasileira no século XXI que permita conjugar a política externa e a política de defesa (Amorim, 2015), e, mais especificamente, para a atualização e reformulação da estratégia de defesa brasileira.

Desse modo, em primeiro lugar, é apresentada uma breve descrição do pré-sal. A seguir são apresentadas, de forma breve, as principais tendências geopolíticas e de longa duração ${ }^{1}$ consideradas determinantes para a construção de cenários de ameaças à soberania brasileira de seus recursos naturais e petrolíferos. São elas: (I) o aumento da competição entre os Estados, especialmente da competição global entre as grandes potências, associada à progressiva horizontalização de capacidades militares e tecnológicas das potências emergentes e a construção progressiva de um sistema internacional multipolar; (II) o aumento da competição global entre as grandes potências pelo controle dos recursos energéticos; (III) o aumento da competição entre as grandes potências pelo controle dos mares e oceanos, desde a competição pelo controle de rotas marítimas, até os recursos marinhos e do subsolo marinho; e, por fim, (IV) o aumento da competição global entre as grandes potências diante dos processos de formação de blocos regionais, especialmente dos processos de integração regionais liderados por potências emergentes, ou que podem vir a se constituir em novos polos do sistema internacional.

Por fim, a partir da análise das tendências geopolíticas supracitadas, busca-se analisar as possíveis modalidades de ameaças para os Estados, especialmente os países emergentes. A seguir elencam-se as decorrentes considerações necessárias para a construção de cenários de ameaças para o Brasil na defesa de seu território, povo e recursos naturais, com foco nas ameaças à soberania brasileira sobre o pré-sal. Assim, o objetivo específico último desta análise é a construção de uma primeira tipologia das ameaças aqui consideradas, para viabilizar a construção futura de cenários em outros trabalhos, ${ }^{2}$ que possam ser atualizados com maior frequência nos próximos anos, especialmente considerando as necessidades de moderni- 
zação constante da estratégia de defesa do Brasil no século XXI. Importa ressaltar que não se pretende, neste trabalho, construir cenários completos, mas focalizar esforços na construção da tipologia de cenários possíveis, aqui organizada em três grupos de cenários não necessariamente completamente excludentes.

\section{O PRÉ-SAL}

O "pré-sal" é uma área que possui uma camada rochosa do subsolo marinho com ricas reservas petrolíferas, localizada sob uma profunda camada de rochas evaporíticas, também conhecidas como rochas salinas ou salíferas. Esta área é formada predominantemente por rochas reservatório e, também, por rochas geradoras de petróleo. Em termos legais, os poços petrolíferos do "pré-sal" são aqueles delimitados na área definida no inciso IV do caput do artigo $2^{\circ}$ da Lei $n^{\circ} 12.351 / 2010$ (Brasil, 2010). As reservas do pré-sal encontradas no litoral do Brasil foram, à época de sua descoberta, as mais profundas em que já foi encontrado petróleo em todo o mundo. Representam também o maior campo petrolífero já encontrado em uma profunda região abaixo das camadas de rochas salinas ou evaporíticas.

Em janeiro de 2017, a produção de petróleo no Brasil totalizou 2,687 milhões de barris por dia (bbl/d), sendo que a extração de petróleo do pré-sal correspondeu a aproximadamente 1,588 milhão de barris de óleo equivalente por dia, ou $47 \%$ do total nacional. A extração petrolífera na região do pré-sal, realizada atualmente através de 73 poços, foi de aproximadamente 1,276 milhão de barris de petróleo por dia e 49,5 milhões de metros cúbicos de gás natural por dia, um aumento de $1,1 \%$ em relação ao mês anterior. O campo de Lula, na Bacia de Santos, se consolidou como o maior campo produtor de petróleo e gás natural do Brasil, com uma média de 729,5 mil bbl/d de petróleo e 31,6 milhões $\mathrm{de}^{3} / \mathrm{d}$ de gás natural (ANP, 2017). 
RBED, v. 3, no 2, jul./dez. 2016

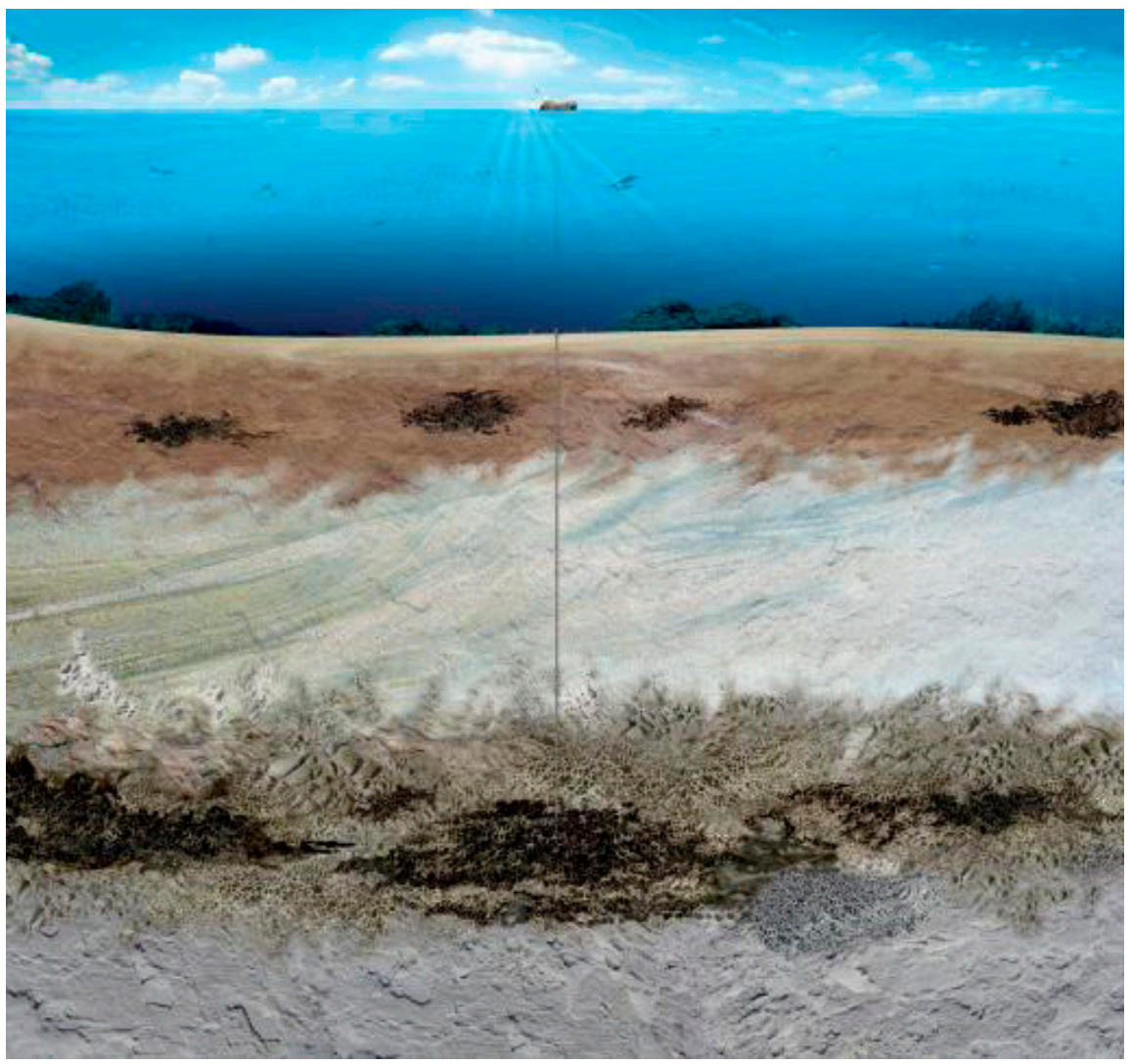

Figura 1 - Petróleo na Camada Pré-sal.

Fonte: Petrobrás (2017). 


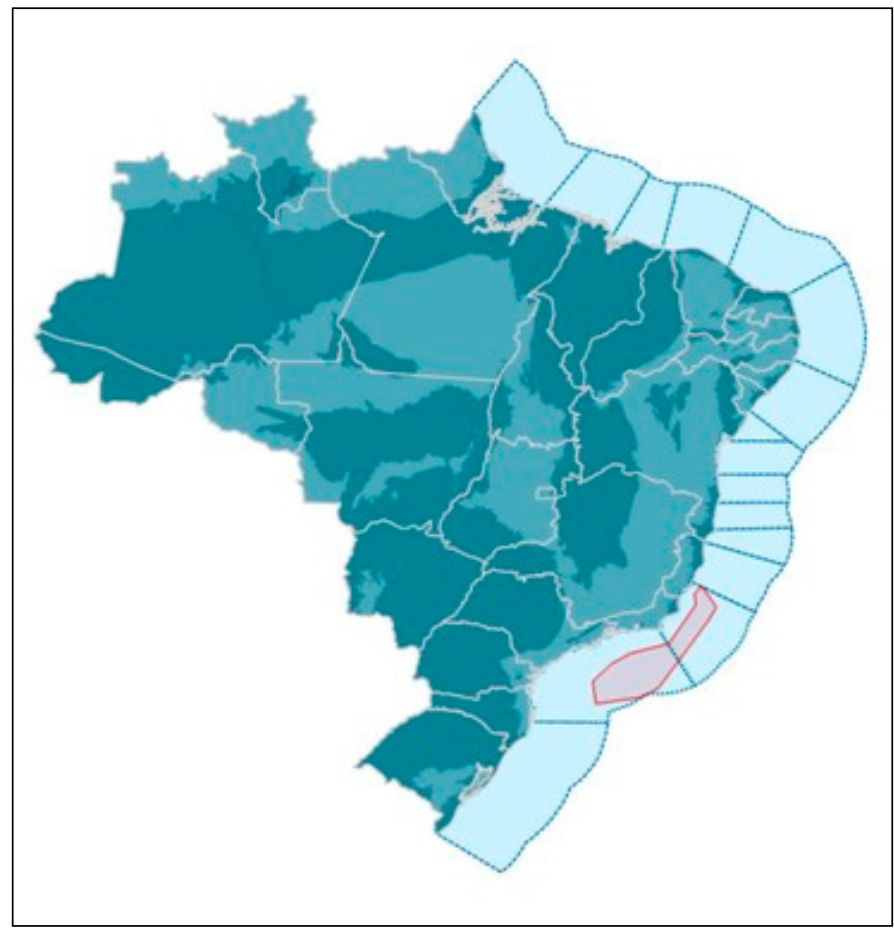

Figura 2 - O Pré-sal no contexto das principais bacias petrolíferas do litoral brasileiro.

Fonte: Petrobrás (2017).

Destaca-se que a Petrobrás cresceu significativamente durante os anos 2000, saltando de um valor de mercado de apenas US $\$ 18$ bilhões, no início de 2003, para mais de US $\$ 200$ bilhões em 2010, década em que a malha de gasodutos dobrou (de $2.762 \mathrm{~km}$ em 2002 para $5.416 \mathrm{~km}$ em 2009) e o peso da empresa no PIB também, passando de 5\% em 2002 para 10\% em 2010 (Estadão, 2009; Landim, 2010).

Ademais, existe um grande potencial para a prospecção e exploração de novas reservas nas bacias petrolíferas do Atlântico Sul, especialmente considerando as bacias geologicamente similares encontradas em ambos os lados deste oceano, tanto na Âfrica como na América do Sul, com ricas reservas petrolíferas já identificadas. Isto tende a manter o Atlântico Sul entre as regiões mais importantes para a expansão da extração petrolífera global, especialmente offshore, com grandes implicações para as disputas geopolíticas pelo controle dos mares e oceanos, como será discutido mais a frente. 


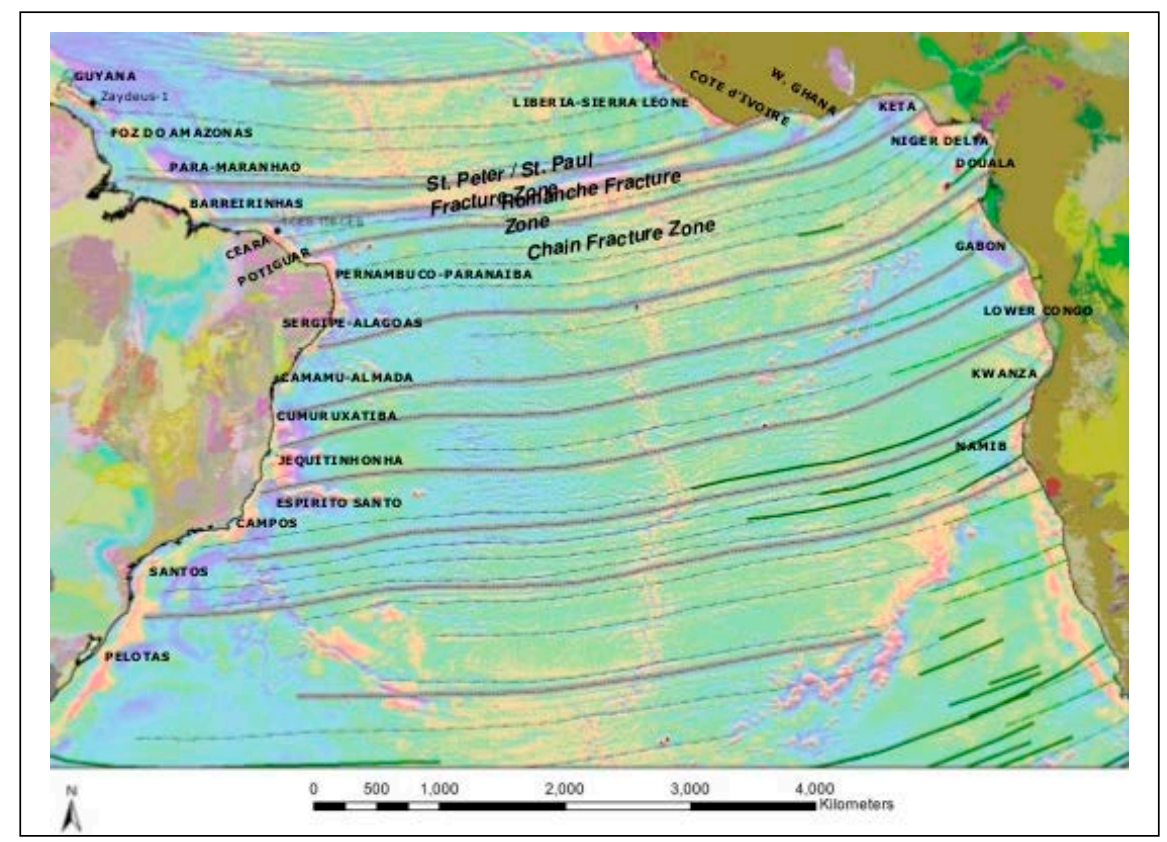

Figura 3-Similaridade Geológica entre as Bacias Sedimentares africanas e sul-americanas com potencial petrolífero no Atlântico Sul.

Fonte: Maersk Oil (2013).

Geopolítica da competição global entre as grandes potências: horizontalização de capacidades e a emergência de um mundo multipolar

O processo de ascensão dos países emergentes, em especial dos países do grupo BRICS, Brasil, Rússia, China e Africa do Sul (Carmona 2014; Fiori 2009; Hurrell et al. 2009; Vizentini 2008; Visentini, 2013; Pautasso, 2011), estaria diretamente ligado à primeira tendência geopolítica a ser analisada: (I) a tendência relativa de horizontalização das capacidades militares entre as grandes potências, advinda da revolução tecnológica e da digitalização (Quedi Martins, 2008; Ávila, Quedi Martins \& Cepik, 2009). Além dessa tendência consistir no pano de fundo que tornou o sistema internacional progressivamente multipolar (embora de forma assimétrica e desigual), pode vir a favorecer o aumento da recorrência de guerras indiretas e locais, em detrimento da probabilidade de erupção de uma guerra central de caráter global. Caso isso ocorra, as devastadoras guerras centrais entre as grandes potências, que historicamente serviram para 
reescalonar e reequilibrar a correlação de forças entre os polos de poder do sistema internacional (Mearsheimer, 2001), podem vir a ser substituídas (parcial ou totalmente) por um enfrentamento mais indireto, embora também violento, caracterizado especialmente pela ocorrência de guerras locais e regionais (Quedi Martins, 2008) ou, ainda, da proliferação de guerras indiretas e por procuração (guerras proxy) entre os polos de poder do sistema (Kerr Oliveira, Pereira Brites \& Silva Reis, 2013; Piccolli, Machado, \& Monteiro, 2016).

Estas guerras locais seriam travadas principalmente entre as grandes potências e Estados ou regiões que são áreas de influência, portanto, objeto das disputas entre os principais polos de poder do sistema internacional. Em um contexto internacional competitivo e instável torna-se mais provável a ocorrência de disputas por áreas de influência entre os polos de poder do sistema internacional. Neste contexto, o controle de recursos naturais estratégicos, em especial os recursos energéticos, como petróleo e gás, continuará sendo objeto de disputa entre as potências que buscam acumular mais poder em termos relativos (Kerr Oliveira, 2012).

Esta é uma tendência para as primeiras décadas do século XXI, que é resultante das disputas centrais do século XX, especialmente dos resultados da confrontação geoestratégica entre EUA e URSS durante a Guerra Fria, em que o equilíbrio nuclear tornou progressivamente mais difícil um confronto direto (Freedman, 2003). A partir daquele período, as grandes potências passaram a restringir o nível de enfrentamento de forma a evitar uma guerra direta, limitando a estratégia de confronto a uma série de disputas indiretas, especialmente por áreas de influência e através de guerras proxy.

Esta estratégia de enfrentamento indireto não se limitou ao período da Guerra Fria, e, tudo indica, tornou-se o padrão de confronto entre as grandes potências. Caso esta tendência se concretize, é possível aferir que esta modalidade de enfrentamento indireto pode tornar-se um dos principais padrões de interação entre as grandes potências. Em um mundo multipolar isso pode significar uma forma de "Guerra Fria" anárquica de todos contra todos (Moniz Bandeira, 2013), em que o nível de tensão entre uma grande potência e as demais, tenderia a depender mais de fatores geopolíticos, embora possa continuar sendo afetado também por mudanças e incertezas conjunturais.

Com a intensificação da competição internacional entre potências ou blocos de Estados, resultante da horizontalização de capacidades militares, os conflitos internacionais potencialmente se apresentariam no formato predominante de enfrentamentos indiretos entre as principais grandes potências, ou seja, sem necessariamente a ocorrência de guerras diretas. Um 
exemplo do crescimento desta competição fortemente militarizada é o atual confronto russo-ucraniano que, em certa medida, é resultado de um confronto geopolítico entre Rússia e EUA, sendo que este último vem apoiando as forças de oposição a Moscou sem realizar uma confrontação direta com os mesmos (Piccolli, Machado \& Monteiro, 2016). Semelhantemente, a disputa entre Rússia, de um lado, e Estados Unidos e Otan, de outro, na guerra civil da Síria, pode ser considerado outro caso de guerra indireta ou uma forma de guerra proxy entre essas potências (Kerr Oliveira, Pereira Brites \& Silva Reis, 2013).

\section{Geopolítica da competição global entre as grandes potências pelo controle dos recursos energéticos}

A segunda tendência geopolítica de longo prazo levada em consideração para esta análise consiste no (II) progressivo aumento da demanda global por energia (CERA, 2006; US-EIA, 2011 e 2016; OPEP, 2016) e, consequentemente, à intensificação das disputas por recursos energéticos. A urbanização e industrialização dos países periféricos, subdesenvolvidos e emergentes, resultado do processo de globalização, apresenta como consequência direta o crescimento da renda e da demanda por recursos naturais, especialmente alimentos e energia. Com o aumento da demanda global por energia nas próximas décadas, torna-se progressivamente mais provável a ocorrência de tensões, crises e conflitos entre os países exportadores de energia e os maiores importadores (Klare, 2001; Kerr Oliveira, 2012; Fuser, 2013). Como cada grande potência busca assegurar sua própria segurança energética, a tendência é de aumento dos conflitos e disputas envolvendo interesses divergentes em relação aos países e regiões petrolíferas (Klare, 2001; Yergin, 2006; Kerr Oliveira \& Pautasso, 2008). Consequentemente, tendem a aumentar as chances de ocorrência de novas guerras por recursos energéticos, especialmente por petróleo, na medida em que as grandes potências tentam controlar cada vez mais diretamente as reservas de recursos energéticos dos países fornecedores (Klare 2001, 2003 e 2008; Kerr Oliveira 2012).

Considerando que as grandes potências, no centro do sistema capitalista, são os maiores consumidores de energia do mundo, pode-se vislumbrar que estas venham a se envolver mais frequentemente nas principais disputas pelo controle de recursos energéticos nas próximas décadas (Klare, 2008; Kerr Oliveira \& Pautasso, 2008; Fuser, 2013). Embora esta tendência, possa ampliar o risco de guerras centrais entre as grandes potências, a natureza destas conflagrações tende a mudar, como veremos a seguir. 
Dentre os resultados do aumento da demanda por recursos energéticos e da competição interempresarial e interestatal por petróleo e gás, um dos resultados é o fortalecimento das tendências nacionalistas nos países exportadores de recursos petrolíferos. Isto tende a ocorrer de forma semelhante ao fortalecimento do "nacionalismo dos recursos" (Fuser, 2013) ocorrido nos anos 2000 em diferentes países petro-exportadores, como na Opep, ou mesmo em países que descobriram novas reservas petrolíferas, como o Brasil (Estadão, 2009). Paralelamente, pode-se esperar o aumento das pressões da opinião pública e dos governos subnacionais pelo aumento do controle nacional sobre a extração petrolífera, na medida em que for crescendo a importância dos royalties, participações especiais e outros dividendos oriundos das atividades petrolíferas no orçamento dos governos (Federal, estaduais e municipais). Se por um lado pode-se verificar uma tendência de aumento do nacionalismo petrolífero e da tentativa do governo de ampliar o controle sobre os recursos energéticos nacionais, por outro, tais políticas tendem a se chocar com outra tendência, a do aumento da cobiça das grandes potências e suas empresas petrolíferas (Xavier Ferolla \& Metri, 2006 e 2008), que podem ver no pré-sal uma alternativa segura e de baixo custo para solucionar a busca por maior segurança energética e maiores taxas de lucro na exploração de petróleo e gás.

\section{Geopolítica da competição global entre as grandes potências pelo controle dos mares e oceanos}

A terceira tendência está relacionada ao (III) aumento do valor geopolítico dos mares e oceanos - em especial, no caso brasileiro, do Atlântico Sul. Este processo está associado a duas tendências principais: (a) o crescimento do comércio marítimo internacional, mesmo para blocos regionais intensamente integrados por via terrestre e, também, (b) a ampliação da importância dos recursos naturais de origem marítima, desde a extração de alimentos (recursos pesqueiros), passando pela obtenção de recursos energéticos (petróleo, gás natural, urânio) ou energia (eólica, maremotriz), até a mineração de minerais metálicos e não metálicos dos mais diversos, incluindo terras raras.

Destaca-se que sob uma perspectiva de longa duração, os oceanos possuíram um papel geopolítico determinante para a construção do sistema internacional e das principais disputas entre as grandes potências ao longo dos últimos séculos, mesmo considerando diferentes perspectivas teóricas ou analíticas (Mahan, 1890; Corbett, 1999; Rasler, \& Thompson, 2005). 


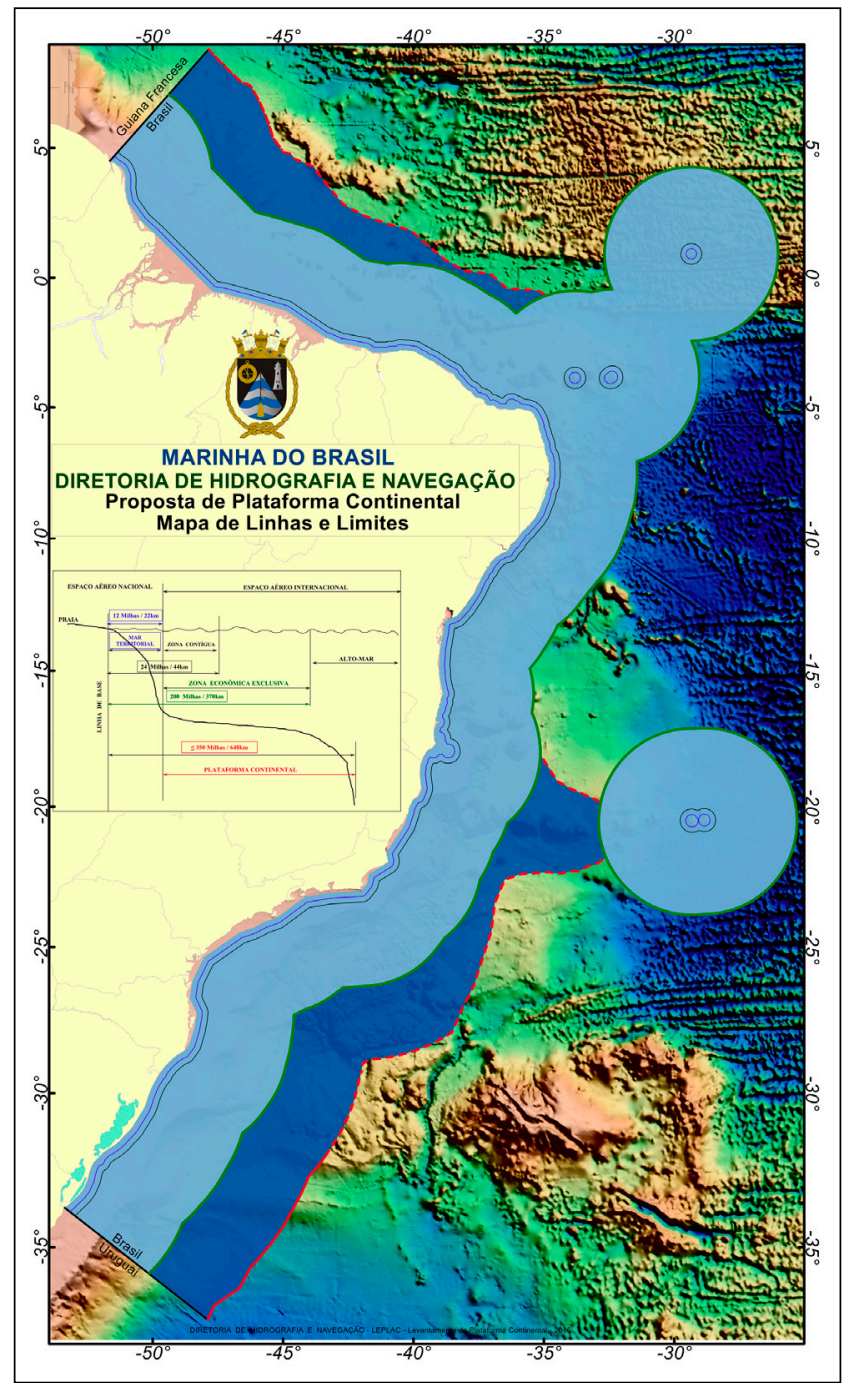

Figura 4 - Águas Jurisdicionais brasileiras, incluindo a Zona Econômica Exclusiva e as áreas da Plataforma Continental Fonte: Marinha do Brasil, LEPLAC (2017).

No caso brasileiro importa ressaltar que o Brasil submeteu à Comissão de Limites da Plataforma Continental da Organização das Nações Unidas (CLCS) um pedido de reconhecimento de inclusão de uma área de 954 mil $\mathrm{km}^{2}$ como parte das suas águas jurisdicionais. A Comissão aprovou o re- 
conhecimento de aproximadamente 90\% desta área, o que levou o Brasil a ingressar com um novo pedido junto à Comissão para o reconhecimento de toda a área (Pereira Silva, 2013; Barros Figueirôa, 2014).

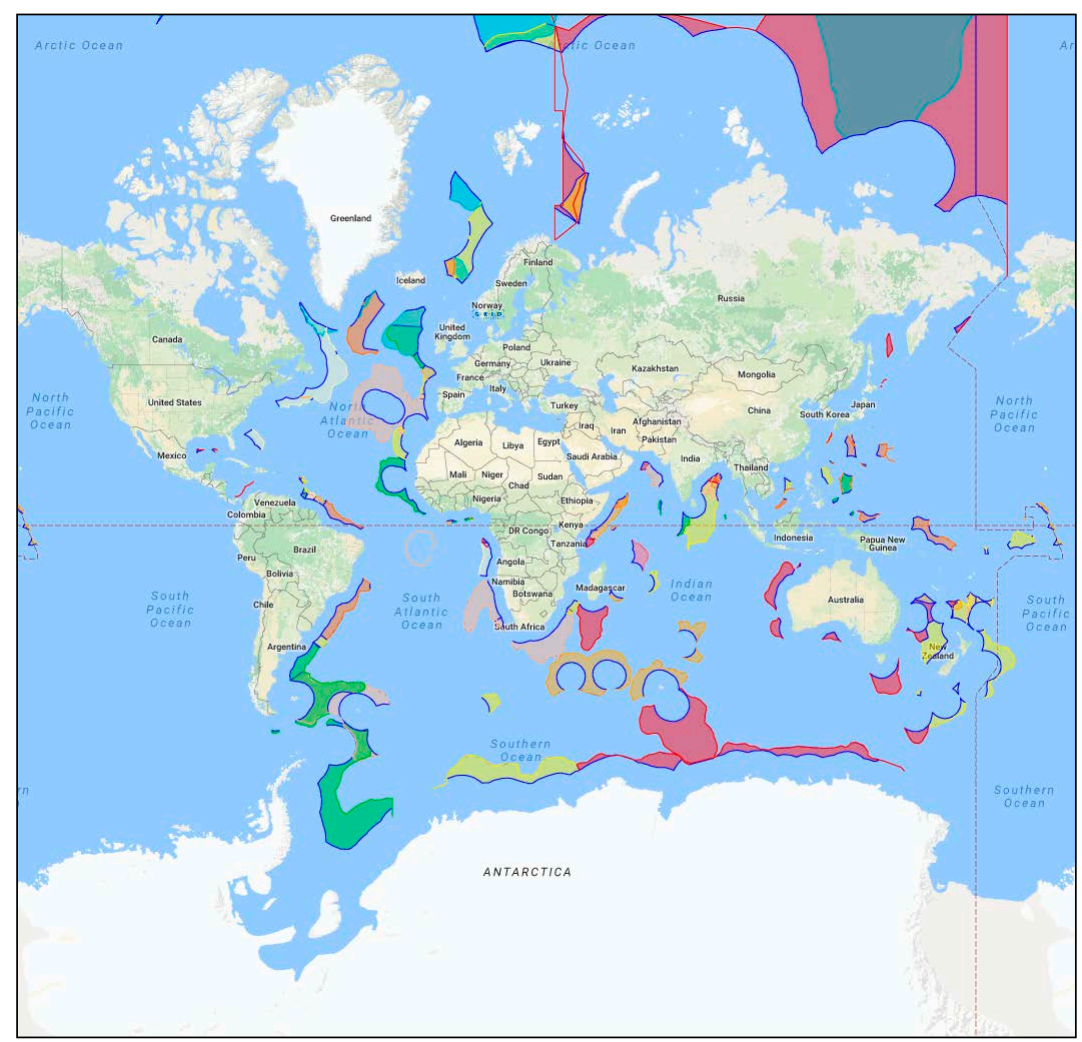

Figura 5 - A Territorialização do Mar: Principais reivindicações territoriais e solicitações de expansão da Zona Econômica Exclusiva junto à ONU

Fonte: GoogleMaps (2017). Mapa interativo ilustrando as reivindicações territoriais e solicitações realizadas pelos Estados membros à Comissão de Limites da Plataforma Continental da ONU.

Deve-se acrescentar, ainda, que atualmente cerca de 30\% da extração petrolífera mundial já é realizada em águas ultraprofundas e esta taxa deve crescer ainda mais nas próximas décadas, em decorrência do esgotamento das reservas mais antigas localizadas nos continentes. Importa acrescentar que, em seguida ao Oriente Médio, os continentes da África e da América do Sul já são as áreas de menor custo para extração de novas reservas de 
petróleo na atualidade e apresentam vantagens para a exploração em alto mar (Kerr Oliveira, 2012).

Isto significa que a descoberta de novos campos de imenso potencial petrolífero nas regiões ultraprofundas da camada pré-sal apresentam enorme potencial para modificar significativamente a importância global desta região entendida como Atlântico Sul, ao mesmo tempo em que despertam a cobiça internacional das grandes potências (Xavier Ferolla \& Metri, 2006 e 2008), alterando definitivamente o peso do Brasil e do seu entorno estratégico na geopolítica do petróleo em escala global.

Destaca-se que alguns dos maiores campos petrolíferos do pré-sal, como Lula, Carioca, Guará e Júpiter, estão localizados no limite das 200 milhas náuticas da Zona Econômica Exclusiva brasileira. Assim, o governo brasileiro publicou uma resolução interministerial, em 2010 (CIRM, 2010), estabelecendo que, independentemente da delimitação do limite exterior da Plataforma Continental (PC) além das 200 milhas náuticas pela ONU, o Brasil tem o direito de avaliar previamente os pedidos de autorização para a realização de pesquisa na sua Plataforma Continental, além das 200 milhas náuticas, tendo como base a proposta de limite exterior encaminhada à Comissão de Limites da Plataforma Continental (Fernandes More, 2012).

Neste contexto, percebe-se que está em andamento uma tendência geopolítica de territorialização dos mares e oceanos adjacentes aos continentes e territórios continentais. Este processo deve se expandir ainda mais nas próximas décadas devido à perspectiva de que a exploração de recursos naturais (alimentos, minerais, energia) venha a ocorrer progressivamente em zonas cada vez mais afastadas do litoral.

Esse processo de territorialização dos mares e oceanos tem implicações significativas para a modernização da defesa do Brasil, na medida em que a dependência do país em relação ao Atlântico Sul tende a crescer progressivamente nas próximas décadas (Caroli, 2010; Danilevicz Pereira, 2013; Wiesebron, 2013), exigindo maiores capacidades de controle e de defesa desta vasta região marítima.

Considerando que o controle de recursos naturais em alto mar já foi objeto de disputas entre potências tradicionais e países emergentes, como na Guerra das Malvinas (1982), ou mesmo em crises que não resultaram em guerras, como no episódio em que a França ameaçou o Brasil com sua Marinha de Guerra, devido à disputa por recursos pesqueiros no litoral brasileiro, durante a crise conhecida como a "Guerra da Lagosta", no início dos anos 1960 (Lessa, 1999; Costa Braga, 2004). A importância destes episódios passados para esta análise reside no fato de que as potências tradicionais continuam dispostas a usar a força em disputas pelo controle de recursos naturais que consideram estratégicos. Se nos anos 1960 a França 
ameaçou o uso da força em uma disputa pela exploração de recursos pesqueiros no litoral brasileiro, parece difícil acreditar que outras potências não estariam dispostas a fazer o mesmo por recursos ainda mais valiosos e estratégicos, como petróleo, no século XXI.

\section{Geopolítica da competição global entre as grandes potências e os processos de formação de blocos regionais}

Por fim, a quarta e última tendência que se destaca para o século XXI refere-se (IV) ao processo de formação de blocos de integração regional. Caso se consolide, a formação de blocos regionais poderá se tornar a base sobre a qual se dará a governança do sistema internacional no futuro, embora a rivalidade entre os blocos regionais também pode se tornar mais frequente.

É interessante ressaltar que nos últimos séculos surgiram novos padrões de Estados, resultantes da intensificação da competição econômica (interempresarial) e político-militar (interestatal) que ampliaram a necessidade das unidades político-econômicas nacionais de assegurarem o acesso a grandes mercados para sustentar a escala necessária à sustentação das indústrias modernas (Chandler, 1994; Chang, 2003 e 2009). Neste contexto, constituíram-se grandes Estados Nacionais, de dimensões continentais e muitas vezes multinacionais, com grandes populações e parques industriais, como no século XX os Estados Unidos e a União Soviética, aos quais se pode acrescentar, no século XXI, gigantes como a China e a Índia, que alteraram definitivamente os termos da competição internacional (Pinheiro Guimarães, 2006; Fiori, 2009). Destarte, aos Estados menores e menos poderosos resta a solução de se unirem e se integrarem em blocos, a fim de evitar que se tornem insignificantes e inviáveis e acabem sendo dominados pelas grandes potências.

Neste contexto, para países semiperiféricos emergentes como o Brasil, torna-se vital fortalecer o avanço da cooperação e da integração regional sul-americana. Nesta região observamos avanços, mesmo que lentos, na conformação no aprofundamento da cooperação e integração de políticas de segurança e Defesa no âmbito da Unasul. Isto pode levar à possível transformação da América do Sul em uma unidade geopolítica, com significativa capacidade para assumir peso estratégico global, podendo esta ilha-continente constituir-se em um dos polos de poder de um mundo progressivamente mais multipolar (Pinheiro Guimarães, 2006 e 2007; Vizentini \& Wiesebron, 2006; Messias Costa, 2009; Vizentini, 2003 e Visentini, 2010).

Isso só será possível caso o Brasil adote a política de arcar com os custos da integração regional, ou seja, incentivar, desenvolver e aprofundar 
os diferentes eixos da integração, que vão muito além do comércio, e referem-se à integração político-institucional, à integração econômica e de cadeias produtivas, da superação das disparidades, da infraestrutura logística da integração (transportes, energia, comunicações), e das políticas de segurança e defesa comuns. Quanto mais integrada, maior será a estabilidade relativa da América do Sul, com óbvias implicações para a segurança do Brasil (Vizentini 2003, 2008 e 2010; Messias Costa, 2009; Dall'Onder Sebben, 2014). Esta tendência tem múltiplas implicações para a atualização da estratégia de defesa nacional, na medida em que impõe a necessidade de se incorporar de forma definitiva ao pensamento nacional o desafio de fomentar progressivamente a cooperação em segurança e defesa entre os países sul-americanos. Dessa forma, elimina-se o risco de guerras locais na América do Sul e constitui-se, no futuro, uma forma institucionalizada de aliança regional de defesa contra ameaças representadas por potências ou blocos rivais extrarregionais.

\section{IMPLICAÇÕES E DESAFIOS PARA O BRASIL: A NECESSIDADE DE CONSTRUÇÃO DE CENÁRIOS DE AMEAÇAS À SOBERANIA SOBRE O PRÉ-SAL PARA SUBSIDIAR A MODERNIZAÇÃO EM DEFESA}

Tendo como ponto de partida o contexto destas quatro grandes tendências geopolíticas estruturais de longo prazo, pode-se prospectar três possíveis modalidades de ameaças militares à soberania brasileira sobre o pré-sal no curto e médio prazo (entre uma e três décadas, ou seja, para aproximadamente 2030 a 2050). Tendo em vista que a formulação de uma estratégia de defesa de longo prazo não pode se basear apenas nos cenários mais prováveis e otimistas (que geralmente tem consequências mais brandas), mas deve considerar, especialmente, os cenários de maior risco, ou seja, mais pessimistas, pois estes implicam nas consequências mais catastróficas e deletérias para um Estado - as considerações aqui desenvolvidas visam a subsidiar prioritariamente os cenários mais pessimistas. Considerando a elevada margem de incerteza política e estratégica advinda de um sistema internacional, que, até o presente, tem se mostrado progressivamente mais competitivo, instável e violento, é fundamental que a formulação de uma estratégia de defesa nacional considere a preparação para o enfrentamento dos piores cenários, ou seja, a preparação para enfrentar, inclusive, uma guerra contra uma potência ou potências extrarregionais. Afim de subsidiar o debate sobre a construção destas modalidades de cenários, prossegue-se com a construção de uma tipologia das ameaças pertinentes para cada modalidade de cenário a ser construída. 


\section{Modalidades de ameaças para a primeira metade do século XXI: considerações para a construção de uma tipologia}

A prospecção de ameaças à soberania brasileira no pré-sal pode utilizar-se de diferentes métodos analíticos. Para os fins deste texto, consideramos como pré-requisito para a construção de cenários prospectivos de ameaças a identificação de eventos recorrentes na História, como determinadas modalidades de operações militares envolvendo disputas por recursos energéticos. Como a guerra é um fenômeno constante e recorrente na História Humana, são aqui analisados aspectos pontuais, que especificamente imponham ameaças à soberania brasileira do pré-sal e de suas águas jurisdicionais.

O pressuposto básico, portanto, desta análise é que as guerras travadas pelo controle de recursos energéticos têm sido recorrentes na história recente da humanidade. Além disso, as guerras por recursos petrolíferos vêm se intensificando ao longo do século XX e das primeiras décadas do século XXI (Klare, 2001 e 2008; Shah, 2007; Kerr Oliveira, 2012; Yergin, 1992 e 2006). Estes elementos são centrais para a análise dos cenários de ameaças possíveis nas próximas décadas, em que um sistema internacional progressivamente multipolar pode se consolidar como mais pacífico ou mais instável e violento. Para um país como o Brasil, isto significa ter que se preparar para diferentes cenários, que podem variar muito, desde ataques indiretos (como os típicos da Guerra Fria), até ataques diretos, na forma de uma guerra aberta, deflagrada por virtualmente qualquer uma das grandes potências.

Para os fins desta análise, considera-se que atualmente as principais grandes potências são EUA, Rússia e China, e que estes continuarão a ser ao longo da primeira metade do século XXI, compartilhando a governança do sistema internacional com um grupo ainda não totalmente definido de outras grandes potências e potências médias regionais (Ávila, Quedi Martins \& Cepik, 2009). Dentre as potências, ou Estados candidatos a participarem do concerto das grandes potências, destacam-se desde Estados nacionais que são potências tradicionais que poderiam ser classificadas como potências médias regionais, como Japão, Inglaterra, França, Alemanha, como países emergentes como Índia, Brasil, Turquia, Indonésia, Nigéria e África do Sul. Tudo indica que a participação de algumas das potências tradicionais, assim como de alguns dos países emergentes, no rol das grandes potências dependerá da capacidade destes Estados de enfrentarem os desafios tecnológicos, militares e geopolíticos vigentes, e, portanto, da capacidade destas potências para lidar com seus respectivos processos de integração regionais. 
Assim, é muito provável que blocos de Estados - como a União Europeia, Unasul e Asean, entre outros -, caso logrem sucesso em aprofundar seus respectivos processos de integração regional, possam vir a assumir, no futuro, a função de polo de poder do sistema internacional. Entretanto, para que isto ocorra, estes blocos devem constituir processos de integração com elevado grau de institucionalização, que permita a consolidação de alianças regionais ou a formação de confederações/federações, mas, principalmente, só será possível caso estes blocos venham a constituir alianças militares sólidas e/ou construir forças de defesa coletivas.

\section{Considerações iniciais para a prospecção de cenários de ameaças} à soberania brasileira do pré-sal

Considerando estas perspectivas, foram prospectadas três modalidades de ameaças militares que, quando detalhadas, podem ser decompostas ou analisadas em diferentes níveis ou tipos de agressões à soberania nacional. Estes três cenários envolvem em algum nível a participação (direta ou indireta) de Estados que podem ser considerados potências extrarregionais adversárias.

O primeiro tipo de ameaça viria do (I) apoio de uma potência agressora a insurgentes armados ou separatistas extremistas no nível subnacional, com vistas a ameaçar a estabilidade institucional do país e sua integridade territorial, e/ou ameaçar, danificar ou destruir infraestruturas críticas essenciais, incluindo navios e plataformas petrolíferas em alto-mar. A segunda categoria de ameaça seria composta pelo (II) apoio de uma potência agressora a governos ou grupos insurgentes subnacionais localizados nos países vizinhos do Brasil. Este cenário consistiria em uma ameaça às fronteiras nacionais, como forma de enfraquecer a capacidade de exercício da soberania sobre o território, desviando recursos necessários para a defesa da soberania das águas jurisdicionais do Brasil no Atlântico Sul. A terceira forma de ameaça seria aquela em que (III) uma potência agressora utilizaria da ameaça ou uso efetivo da força diretamente contra o Brasil, especialmente através de forças aeronavais deslocadas ao Atlântico Sul para ameaçar o pré-sal e o litoral brasileiro. Como fica claro, o pior cenário é resultante da conjugação de duas ou três categorias acima explanadas. 


\section{1) Considerações para a construção de cenários de ameaça à soberania sobre o Pré-Sal em que uma Potência agressora se utiliza de ameaça subnacional/local para enfraquecer o Brasil}

Importa destacar que o uso de uma ameaça subnacional ou local, apoiada e armada por uma potência inimiga, é das perspectivas mais complexas e controversas. Isto porque, embora existam ameaças à soberania dos Estados de origem interna, como a ameaça representada por possíveis movimentos separatistas, outras formas de ameaças internas mostraram-se bastante difusas e menos relevantes. Ademais, embora seja complexo, é necessário escalonar tais fontes de insegurança para melhor avaliá-las separadamente e planejar formas de evitá-las antecipadamente. Geralmente as reais ameaças internas à sobrevivência de um Estado são aquelas que podem levar à fragmentação territorial e o consequente fim da unidade geográfica ou entidade política, ou ainda, o completo colapso das instituições políticas e da capacidade de governar seu próprio território.

Esta modalidade de ameaça, muitas vezes, se mistura com facilidade às ameaças de ordem menor, que historicamente não representam uma ameaça urgente à sobrevivência de um Estado. Entretanto, mesmo ameaças menores à segurança pública e institucional, podem desestabilizar governos, como o problema da segurança pública ou processos de desestabilização institucional, que podem levar à ruptura institucional, na forma, por exemplo, de um golpe de Estado, caso sejam impulsionadas por potências extrarregionais agressoras. Para isso, é fundamental identificar as múltiplas fontes possíveis para o desenvolvimento de ameaças à segurança e estabilidade institucional. Nesse sentido, é basilar que os aparatos de segurança do Estado consigam separar claramente os níveis analíticos da segurança nacional, da segurança institucional e da segurança pública, assim como a modalidade de resposta defensiva ou securitária que será adotada.

Outra razão porque esta modalidade de problemas locais é complexa refere-se justamente ao fato de que muitos governos historicamente, e ainda na atualidade, misturam a natureza destas ameaças para justificar respostas mais duras do que o necessário. Com o objetivo de assegurar a sobrevivência do governo no curto prazo, mesmo quando isto possa representar o enfraquecimento do Estado no longo prazo, utilizam-se de medidas de força de intensidade incompatível com a ameaça real apresentada. Os casos mais comuns seriam aqueles ligados à construção da percepção de que determinado grupo político de oposição seria uma ameaça, apenas para justificar a elevação dos níveis de repressão interna.

Os exemplos dessa natureza aparecem em inúmeros momentos na história humana, mas é particularmente significativo na América Latina, 
durante a Guerra Fria. Quando a perseguição política a grupos nacionalistas e de esquerda era justificada pela ameaça representada pelo suposto inimigo interno do "comunismo" (Mares, 1995; Rapoport \& Laufer, 2000; Victoriano Serrano, 2010; Mitre, 2010), mesmo nos casos em que a divergência central entre os grupos políticos da época fosse centrada no caminho a ser adotado para o desenvolvimento do país.

Contudo, a variedade de possíveis ameaças à segurança institucional torna-se mais complexa diante das perspectivas de que potências extrarregionais venham a desestabilizar o governo através do uso de técnicas midiáticas inovadoras e complexas, combinadas com o financiamento de "revoluções coloridas", ou mesmo de "guerras híbridas". Tais táticas teriam como objetivo o vetor de menor custo, ou seja, a derrubada do governo instituído e sua substituição por outro disposto a simplesmente abrir mão do controle nacional dos recursos petrolíferos, optando por entregar o pré-sal e outros recursos petrolíferos para as corporações multinacionais petrolíferas estrangeiras. Neste sentido, a concretização desta modalidade de cenário dependeria da eliminação de posições hegemônicas ou até consensuais no nível nacional, que apregoam o maior controle nacional possível sobre os recursos energéticos.

Destarte, ameaças internas continuam existindo na atualidade, mas fica cada vez mais claro que não advém de problemas de segurança pública tradicionais (estes se internacionalizaram ou tornaram-se transfronteiriços), mas sim de ameaças concretas como a de novas formas de extremismos ou separatismos. Estes grupos ressurgidos no século XXI podem receber apoio e serem armados por uma potência extrarregional. O neosseparatismo ameaça não apenas a integridade territorial dos países sul-americanos, como no recente caso da crise boliviana de 2006-2009 (Dall'Onder Sebben, 2007, 2010 e 2014; Cepik, 2008 e 2010; Chossudovsky, 2008), como pode se constituir em uma ameaça ao processo de integração regional na América do Sul. Considerando que a integração regional é vital para que os países da região venham a obter maior autonomia e soberania (Pinheiro Guimarães, 2007; Moniz Bandeira, 2008; Messias Costa, 2009; Vizentini, 2003, 2008 e Visentini, 2010), especialmente diante da intensificação da competição internacional e para fazer frente à ameaça do neoimperialismo das potências tradicionais, o separatismo apoiado por uma potência agressora aparece como a maior ameaça de nível subnacional/local, pois é a única ameaça interna capaz de simultaneamente ameaçar a democracia, a soberania e a integridade territorial brasileira (Dall'Onder Sebben, 2010 e 2014).

Neste caso, pode-se projetar que as unidades governamentais subnacionais em que estão localizadas as maiores reservas de petróleo e que possuem grandes desigualdades socioeconômicas, podem estar entre as 
mais propensas ao surgimento deste tipo de ameaça. $\mathrm{O}$ financiamento ou armamento de tais grupos armados insurgentes poderia vir tanto através de empresas petrolíferas estrangeiras como diretamente de governos das grandes potências, como já ocorreu em casos de outros países exportadores de petróleo e gás natural na África e América do Sul (Dall'oOnder Sebben, 2007 e 2014; Santos Xavier, 2009; Kerr Oliveira, 2012). Este financiamento poderia impulsionar o surgimento de movimentos ou grupos insurgentes armados de caráter separatista-extremista em alguma unidade política subnacional (estadual ou municipal) localizada próxima ao pré-sal, constituindo uma ameaça direta contra a integridade territorial e à soberania do Brasil (Kerr Oliveira, 2012).

Importa destacar que existem diversos indícios que as grandes potências e suas companhias petrolíferas apoiaram movimentos separatistas, ou outros tipos de insurgentes armados, em províncias petrolíferas de países petro-exportadores, por exemplo, no continente africano (Santos Xavier 2009; Kerr Oliveira, 2007). No caso de um grupo desta natureza conseguir deflagrar uma crise de insegurança pública, realizar atentados terroristas ou ataques contra forças do governo ou contra civis, de forma a provocar uma crise institucional, isto poderia vir a legitimar uma intervenção "humanitária” por parte das grandes potências interessadas no petróleo brasileiro (Diallo Mamadou, Fernandes \& Garcia, 2011).

\section{II) Considerações para a construção de cenários de ameaça à soberania sobre o Pré-Sal em que uma Potência agressora se utiliza da desestabilização da América do Sul para enfraquecer ou ameaçar o Brasil}

A possibilidade de que disputas locais entre países vizinhos da América do Sul resulte em uma guerra de escala local ou regional, parece ser bastante reduzida nos dias de hoje. Contudo, cresce significativamente a probabilidade de que conflitos desta natureza ameacem o Brasil, especialmente considerando as rivalidades históricas regionais e as disputas fronteiriças não completamente solucionadas que ajudam na manutenção destas rivalidades. Isto torna-se particularmente preocupante no caso de uma potência extrarregional decidir implementar uma política de incentivo ou subsídio a tais rivalidades locais. Estes subsídios poderiam vir em diferentes formatos, desde o apoio político-diplomático, até o financiamento direto a Estados ou grupos não estatais, incluindo a distribuição de armamentos para grupos terroristas, extremistas separatistas, ou grupos guerrilheiros insurgentes com discurso ou prática claramente anti-Brasil, ou contrários à integração regional sul-americana. Ademais, o apoio de uma ou mais potências extrarregionais a grupos extremistas separatistas e terroristas, especialmen- 
te em países politicamente e/ou socialmente mais polarizados, implica em um perigoso potencial para desestabilizar o entorno estratégico do Brasil na América do Sul (De Conti Pagliari, 2009; Mattar Nasser \& Fracalossi Moraes, 2014). Especialmente se tal processo resultar na ruptura político institucional ou até mesmo em guerras civis nestes países, que poderiam resultar em guerras locais-regionais (Chossudovsky, 2008; Cepik, 2008; Dall'Onder Sebben, 2014; Kerr Oliveira, 2014).

Esta modalidade de estratégia, por parte de uma potência extrarregional, pode ter por objetivo simplesmente dividir os países sul-americanos, para impedir que estes atuem em bloco contra seus interesses. Mas pode, também, enfraquecer a liderança regional brasileira, jogando aliados regionais contra o Brasil (Friedman, 2012). Destarte, pode desviar a atenção, os recursos e esforços nacionais que poderiam ser utilizados na defesa do pré-sal e na segurança do Atlântico Sul, ou mesmo na consolidação da integração regional sul-americana. Esta questão poderia ser explorada por elites políticas locais que ganhariam, no curto prazo, com a implementação de uma política contrária a qualquer projeto de integração.

Importa ressaltar que inúmeras disputas fronteiriças e rivalidades históricas na América do Sul persistem na atualidade e estas representam uma complexa mistura de diferentes formas de ameaças à paz na região. Especialmente quando estas disputas são habilmente exploradas por uma potência extrarregional que dispõe dos mecanismos político-militares e de inteligência adequados para incentivar e fomentar guerras civis ou interestatais locais ou regionais.

Historicamente o continente sul-americano foi marcado por uma série de guerras ou ameaças de guerras envolvendo disputas fronteiriças, desde as guerras de independência dos países da região. Os confrontos interestatais regionais foram uma constante na América do Sul nos últimos dois séculos. Destacam-se inicialmente o longo ciclo de guerras platinas (Guerra da Cisplatina, 1825-1828; Guerra do Prata ou contra Oribe e Rosas, 1851 a 1852; Guerra civil no Uruguai ou Guerra contra Aguirre, 1864 e 1865), que culminaram na Guerra da Tríplice Aliança contra o Paraguai (1864-1870) e a Guerra do Pacífico (1879-1883). Mesmo os limites fronteiriços delimitados pacificamente até a virada do século XIX para o XX foram marcados por inúmeras tensões e ameaças de conflagrações. No século XX, pode-se citar outros confrontos interestatais, como os que ocorreram entre Colômbia e Peru na região de Letícia (1933-1934), a sangrenta Guerra do Chaco (1932-1935) e as Guerras entre Peru e Equador (1941, 1981, 1995). Nota-se que os confrontos armados interestatais bilaterais no continente sul-americano reforçaram a percepção de muitos destes países de que seus vizinhos eram a maior ameaça à sua soberania, 
moldando assim toda uma tradição de estratégias e doutrinas que consideravam o vizinho uma ameaça.

A ameaça de guerras bilaterais envolvendo disputas fronteiriças continuou existindo ao longo das últimas décadas (Briscoe, 2010; Brigagão, 2010), como no caso das disputas Argentina-Chile nos anos 1970 e 1980, ou através da manutenção de certas rivalidades na relação Peru-Equador, na retomada das rivalidades Colômbia-Venezuela nos anos 2000 e no surgimento de tensões pontuais entre Colômbia e Equador e Chile e Bolívia. Estes casos reforçam a hipótese de que rivalidades antigas podem vir a ser facilmente reativadas quando não foram adequadamente resolvidas, especialmente quando existirem interesses exógenos em fomentar a instabilidade na América do Sul (Cepik, 2005, 2008 e 2010; De Conti Pagliari, 2009; Mattar Nasser \& Fracalossi Moraes, 2014; Moniz Bandeira, 2008 e 2013; Pinheiro Guimaraes, 2006 e 2007; Vizentini, 2003).

\section{III) Considerações para a construção de cenários de ameaça à soberania sobre o Pré-Sal em que uma Potência agressora usa da força para ameaçar ou atacar o Brasil}

Dentre as consequências já citadas do aumento da competição entre as grandes potências e do seu ativismo progressivo em defesa dos seus interesses energéticos, destaca-se a generalização de políticas que buscam aumentar o conrole, da forma mais direta possível sobre as reservas de recursos energéticos dos países fornecedores (Klare, 2001, 2003, 2006, 2008; Fuser, 2008 e 2013). Isto tende a se manifestar na forma de um novo ciclo de disputas interestatais, em que o neointervencionismo e o neoimperialismo das grandes potências acaba impulsionando a formação de coalizões anti-imperiais regionais para resistir a essas investidas. Nesta modalidade de contexto, as regiões que demorarem mais tempo para integrar suas políticas de segurança e defesa mais facilmente podem se tornar alvo da política das grandes potências.

Para este cenário de ameaças, podemos resgatar diversos exemplos na história. Porém, o mais significativo para esta análise consiste na Guerra das Malvinas (1982), por ter ocorrido na América do Sul e por seus desdobramentos serem sentidos até os dias de hoje na formulação da política externa e de segurança do Brasil e da região (Moniz Bandeira, 2012).

A disputa pelas Malvinas remonta ao século XIX, quando a Inglaterra invadiu e anexou o arquipélago como um enclave colonial a partir de 1833. As ilhas possuem grande valor geopolítico e estratégico, por sua localização próxima a passagem entre os Oceanos Atlântico e Pacífico (fato corroborado pela Batalha das Falklands, em 1914, durante a I Guerra Mundial) 
e por permitir a reivindicação de parcela do continente antártico. Não bastassem esses aspectos estratégicos, somam-se fortes interesses econômicos pela posse de uma grande área marítima de 200 milhas no entorno das ilhas, o chamado mar patrimonial ou Zona Econômica Exclusiva (ZEE). Nesta área, a Inglaterra tem, na prática, a exclusividade para a exploração de recursos naturais como a pesca, o turismo ou a extração de petróleo e gás natural. O resultado desta ocupação colonial é que hoje a Inglaterra já possui companhias realizando atividades de exploração de petróleo e gás na região desde o início da década, sendo que em abril de 2015, a empresa inglesa Falklands Oil and Gas anunciou a descoberta de novas reservas na zona ao norte do arquipélago (RT, 2015).

O Brasil, desde o século XIX, apoia a reivindicação argentina sobre o território (Pamplona, 2012). Entretanto, as recentes descobertas do pré-sal trouxeram à tona o espectro da conflagração de 1982, com complexas implicações para a segurança do Atlântico Sul e da soberania brasileira sobre o pré-sal. Não é mera coincidência que a proteção dos recursos naturais, especialmente da Amazônia Azul, ganhou destaque na Estratégia Nacional de Defesa (Brasil, 2008) e no Livro Branco de Defesa Nacional (Brasil, 2012). A defesa dos recursos naturais também se tornou central para os demais países da América do Sul, como é possível constatar através do Estatuto do Conselho de Defesa Sul-Americano da Unasul (2008), em seu artigo 3 alínea j. E é também sob a liderança da diplomacia brasileira que a defesa da reivindicação argentina e o cumprimento das resoluções da ONU de 1965 se tornaram consenso para toda a América Latina, como é possível constatar pelas reuniões de cúpula da Unasul, Mercosul, Celac e Aladi (Pamplona, 2012; Mercopress, 2015).

Esta análise mostra-se pertinente, até aqui, para demonstrar a importância do pré-sal na mudança de percepção de ameaças por parte do Brasil, assim como da importância da integração regional sul-americana no campo da segurança e defesa, para a garantia da paz, estabilidade e soberania da região (Pinheiro Guimarães, 2007; Moniz Bandeira, 2008; Messias Costa, 2009; Vizentini, 2003, 2008 e 2010; Cepik, 2005 e 2008). Neste sentido, importa destacar que o principal consenso atingido até o presente momento na Unasul, envolvendo os debates relativos à percepção de ameaça, é justamente referente à criação de uma estratégia comum para assegurar a soberania dos países sul-americanos sobre os seus respectivos recursos naturais e energéticos. Este consenso, expresso no Estatuto do Conselho de Defesa da Unasul, pode ser exemplificado nesta fala do Secretário-Geral Ali Rodriguez Araque:

[...] ter um continente com potencial de recursos naturais e ter o resto do mundo exigindo esses recursos naturais, razoavelmente 
nos leva a crer que pode haver um ponto de tensão [...] Assistimos um cenário em que haverá lutas globais persistentes pelos recursos naturais. Neste cenário os desafios no que diz respeito à propriedade e alocação de recursos críticos [...] não são imaginários [ [...] os países da UNASUL têm uma oportunidade única para dar um exemplo histórico com relação à abordagem regional para a gestão, o desenvolvimento e o uso dos recursos naturais [...] o Conselho de Defesa Sul-Americano entende que os desafios que terão que enfrentar as políticas de defesa nos próximos anos, seguramente serão atendidos de forma mais satisfatória, na medida em que dermos respostas regionais e não respostas exclusivamente locais ou individuais de cada um dos nossos países" (CEED 2014).

Entretanto, a formulação política e a atuação diplomática brasileira devem ser acompanhadas dos meios necessários para viabilizar sua política de defesa e dissuadir possíveis agressores. Considerando a estratégia vigente e os meios de defesa necessários, pode-se dizer que as capacidades nacionais de defesa naval são insuficientes para enfrentar adequadamente uma potência agressora. Portanto, podem ser considerados insuficientes para realmente dissuadir uma grande potência dotada de meios de projeção de forças aeronavais modernos.

\section{CONSIDERAÇÕES FINAIS}

No nível discursivo, o Brasil adotou em sua formulação de defesa a importância do advento do pré-sal para se repensar a defesa nacional e da região a partir da garantia da soberania de seus recursos naturais. Esta questão foi inserida em documentos oficiais como o Livro Branco de Defesa Nacional, e pode-se perceber também na incorporação da questão da soberania dos recursos naturais nos documentos estratégicos de fundação do Conselho de Defesa Sul-Americano. Entretanto, apesar da formulação política e, inclusive, da definição de metas e objetivos em documentos oficiais e tratados regionais, pode-se notar um sério descompasso com a formulação de uma estratégia de modernização das capacidades de defender a soberania nacional que possa ser considerada uma política de Estado de longa duração, capaz de sobreviver às crises políticas e econômicas enfrentadas na atualidade ou no futuro. Afinal, pouco se refletiu, debateu ou preparou-se para os novos cenários de ameaça recorrentes, que tendem a afetar ou já estão afetando o país neste início do século XXI. Dessa forma, este artigo procurou tipificar esses cenários em três grupos de possibilidades, que potencialmente podem se sobrepor, a partir da análise do sistema internacional hodierno e alguns eventos específicos, a fim de ajudar a vis- 
lumbrar de forma mais clara as possibilidades de ação política para fazer frente a estes desafios. Dentre os resultados desta pesquisa, destaca-se, ainda, a necessidade de desenvolvimento de novos estudos, especialmente a prospecção de cenários detalhados que permitam analisar os impactos de diferentes modalidades de ameaças à soberania brasileira sobre o pré-sal. Tendo em vista a análise aqui desenvolvida, pode-se elencar algumas considerações iniciais com vistas à formulação dos supracitados cenários e de algumas medidas para enfrentar os desafios elencados a partir das diferentes modalidades de ameaças prospectadas.

Para fazer frente as ameaças do tipo I, de ordem subnacional/local incentivadas por potências extrarregionais, é fundamental que o país consiga atualizar e reestruturar as suas instituições voltadas para a manutenção da lei e da ordem no nível interno, ou seja, da segurança pública. É essencial que tais forças tenham capacidade de enfrentar não somente as chamadas "novas ameaças”, especialmente o terrorismo e a insurgência armada, mas também, e principalmente, fazer frente às operações encobertas e ações de espionagem ou sabotagem empreendidas por potências agressoras. Para isso, torna-se fundamental repensar as estruturas dos serviços de inteligência nacionais, especialmente com a criação de novas agências, voltadas exclusivamente para a realização de inteligência e contrainteligência no exterior, com foco nas grandes potências. Igualmente, faz-se necessário, também, assegurar a capacidade de ações de contraespionagem que permitam proteger nossas instituições políticas e a preservação da democracia. Consequentemente, é crítico que nossas forças policiais e de inteligência tenham capacidade de participar do esforço de guerra cibernética para defender o país de operações encobertas que venham a ser construídas para apoiar grupos insurgentes separatistas-extremistas locais. Neste contexto, uma solução apontada por Marco Cepik (2010, 2014) seria a criação de um Ministério de Segurança Institucional, que centralizasse processos decisórios e políticas públicas de segurança atualmente dispersas em estruturas como Secretaria de Assuntos Estratégicos (SAE), Gabinete de Segurança Institucional (GSI) e Secretaria Nacional de Segurança Pública (Senasp/MJ). Neste sentido, é necessário aprofundar a capacidade do Estado de combater o separatismo e o terrorismo, através da construção de tipificações mais rigorosas destas modalidades de crime e de mecanismos mais contemporâneos para enfrentá-los. Isto porque, embora o crime de separatismo esteja claramente delimitado na Constituição Federal e na Lei n ${ }^{\circ}$ 7.170/1983, o mesmo não ocorre no Código Penal ou no Código de Processo Penal. Ademais, o Poder Judiciário e as instituições de segurança pública ainda não estão suficientemente preparadas para combater as novas modalidades de terrorismo e separatismo (Graça Hahn, 2006; Cepik, 2010; Dall'Onder Sebben 2014). Outra política que se 
faz essencial refere-se ao progressivo aprofundamento dos mecanismos de cooperação em segurança regional, no âmbito da Unasul (Amorim, 2009; Cepik, 2008), especialmente através da consolidação da institucionalização de tais estruturas e mecanismos cooperativos.

Para enfrentar as ameaças do tipo II, é essencial que o Brasil consiga conjugar esforços diplomáticos, políticos, econômicos e militares para ajudar a solucionar os conflitos e rivalidades existentes entre os países vizinhos. Além disso é necessário aprofundar a integração regional sul-americana, construindo a infraestrutura da integração (Kerr Oliveira, 2014), favorecendo o estabelecimento de cadeias produtivas integradas regionalmente, especialmente nas indústrias de equipamentos de defesa, de alta tecnologia e de uso dual, favorecendo o crescimento e desenvolvimento socioeconômico e tecnológico no conjunto dos países sul-americanos.

Neste sentido, torna-se determinante que a diplomacia e os recursos de poder brando do Brasil sejam, desde já, direcionados para a resolução de disputas fronteiriças entre os países vizinhos sul-americanos e para a integração das políticas de segurança e defesa com construção de uma base industrial de defesa comum. A Unasul apresenta um grande potencial para a construção de uma comunidade de segurança, com grandes possibilidades de favorecer e institucionalizar a cooperação e integração securitária e de políticas de defesa. Para que isto se viabilize, é fundamental que o principal líder do processo de integração sul-americano, o Brasil, mude sua política para o subcontinente e passe a realmente arcar com os custos da integração regional.

No que tange às ameaças de tipo III, a agressão perpetrada diretamente por uma potência extrarregional, continua sendo determinante a construção de capacidades críveis de dissuasão convencional capazes de desestimular, inibir e, se necessário, barrar e destruir os meios para possíveis agressões diretas. Para isso, a construção de uma estratégia de defesa em camadas (Kerr Oliveira 2012; Kerr Oliveira, Pereira Brites \& Cepik, 2014 ) pode vir a permitir a estruturação de uma defesa mais eficiente em termos dissuasórios. Considerando a extensão das possíveis listas de capacidades militares a serem mantidas, aprimoradas ou desenvolvidas pelas Forças Armadas brasileiras para enfrentar a ameaça de uma potência extrarregional, torna-se imprescindível o desenvolvimento de outros estudos, inclusive específicos para cada força, sistemas de defesa ou plataformas necessárias para a consecução desta estratégia. Considerando o tamanho da costa e a área da ZEE brasileiras a serem protegidas, assim como o volume de riquezas desta área (incluindo o pré-sal), pode-se dizer que é muito reduzido o tamanho e o poder de fogo da esquadra brasileira para enfrentar ameaças dessa natureza. Contudo, a mera expansão quantitativa do nú- 
mero de belonaves não é suficiente para responder a este desafio: faz-se necessária uma expansão devidamente planejada para incorporar o maior número possível de plataformas (navios, submarinos, aeronaves, veículos terrestres), fabricados no Brasil e com capacidades modernas de combate contra marinhas potencialmente agressoras, utilizando-se, por exemplo, de mísseis antinavio de longo alcance e de mísseis de cruzeiro guiados. Isto implica na necessidade de modernização da estratégia de defesa naval (Kerr Oliveira, Pereira Brites \& Cepik, 2014), na modernização das capacidades industriais e de inovação tecnológica associadas à indústria naval (Cavedon Nunes, 2017), e, por fim, na modernização das capacidades de combate no nível tático, operacional e estratégico.

Em suma, torna-se necessário que o Brasil repense seu processo de modernização das capacidades de defesa, constituindo uma política de atualização permanente da estratégia de defesa, em sinergia com a política externa, ou seja, como parte da grande estratégia brasileira de inserção internacional e desenvolvimento nacional. Uma política que permita a modernização constante dos processos de formação, qualificação e treinamento de recursos humanos, de construção de infraestrutura e aquisição de equipamentos adequados para as Forças Armadas, bem como a consolidação de uma base industrial de defesa mais autônoma, inovadora e regionalmente integrada.

\section{REFERÊNCIAS}

Amorim, C. L. (2009). A integração sul-americana. Revista Diplomacia, Estratégia, Política. $\mathrm{n}^{\circ}$ 10, p. 9-21, out-dez/2009, Brasília.

Amorim, C. L. (2015). Grande Estratégia: política externa e defesa em um mundo em transformação. Austral: Revista Brasileira de Estratégia e Relações Internacionais, v. $4, \mathrm{n}^{\circ} 7$, p. 9-21, jan.-jun./2015.

ANP (2017). Produção do pré-sal foi recorde em janeiro. ANP Notícias, 02/03/2017. Portal da Agência Nacional do Petróleo, Gás Natural e Biocombustíveis. Governo Federal. <www.anp.gov.br/wwwanp/noticias/anp-e-p/3608-producao-do-pre-sal-foi-recorde-em-janeiro $>$

Ávila, F. S.; Quedi Martins, J. Q. Q. \& Cepik, M. A. C. (2009). Armas estratégicas e poder no sistema internacional: o advento das armas de energia direta e seu impacto potencial sobre a guerra e a distribuição multipolar de capacidades. Revista Contexto Internacional, vol. 31 , nº 1, p. 49-83. Rio de Janeiro, Brasil.

Barros Figueirôa, C. S. (2014). Limites exteriores da plataforma continental do Brasil conforme o direito do mar. Ed. FUNAG: Brasília, DF. 
Basic Olic, N. (2011). Geopolítica dos Oceanos, Mares e Rios. Ed. Moderna: São Paulo, SP.

Brasil(2008).Estratégia NacionaldeDefesa.MinistériodaDefesa:Brasil. $<$ http://www. sae.gov.br/site/wp-content/uploads/Estrat\%C3\%A9gia-Nacional-de-Defesa. $\underline{\text { pdf }>}$

Brasil (2010). Lei Federal $n^{\circ}$ 12.351, de 22 de dezembro de 2010. Dispõe sobre a exploração e a produção de petróleo, de gás natural e de outros hidrocarbonetos fluidos, sob o regime de partilha de produção, em áreas do pré-sal e em áreas estratégicas; cria o Fundo Social - FS e dispõe sobre sua estrutura e fontes de recursos; altera dispositivos da Lei no 9.478, de 6 de agosto de 1997; e dá outras providências. Presidência da República, Governo Federal, Brasília, DF.

Brasil (2012). Livro Branco de Defesa Nacional. Ministério da Defesa: Brasil. $<\underline{\text { htt- }}$ ps://www.defesa.gov.br/arquivos/2012/mes07/lbdn.pdf>

Brasil (2014). Mapa do pré-sal no Brasil. Área do território brasileiro com potencial de exploração de pré-sal. Portal Brasil, Governo Federal. < $\underline{w w w . b r a s i l . g o v . b r / ~}$ infraestrutura/2014/07/brasilpresal.jpg/view>

Braudel, F. (1982). História e Ciências Sociais. 4ª edição. Editorial Presença: Lisboa, Portugal.

Braudel, F. (1992). História e Ciências Sociais. A longa duração. p. 41-78. In: Raudel, Fernand (1992). Escritos sobre a História. Perspectiva: São Paulo, SP.

Brigagão, C. (2010). [org.]. A América Latina e os Conflitos Fronteiriços. GAPcon/ Educam: Rio de Janeiro, RJ.

Briscoe, I. (2010). Conflictos em la frontera: las nuevas zonas calientes em América Latina. p. 27-48. In: Brigagão, Clóvis (2010). [org.]. A América Latina e os Conflitos Fronteiriços. GAPcon/Educam: Rio de Janeiro, RJ.

Carmona, R. (2014). The return of geopolitics: the ascension of the BRICS. Austral: Brazilian Journal of Strategy and International Relations, v. 3, $\mathrm{n}^{\circ}$ 6, p. 37-72, jul./2014.

Caroli, L. H. (2009). A Importância Estratégica do Mar para o Brasil no Século XXI. Cadernos de Estudos Estratégicos, $\mathrm{n}^{\circ} 09$ (jul.2010) p. 118-157. Centro de EstudosEstratégicos da Escola Superior de Guerra (Brasil). <www.esg.br/images/Revista_e_Cadernos/Cadernos/CEE-009.pdf>

Castro, Therezinha de (1999). Geopolítica. Princípios, meios e fins. Ed. Bibliex: Rio de Janeiro, RJ. 
Cavedon Nunes, R. (2017). Base Industrial de Defesa, Estratégia de Desenvolvimento e Inserção Internacional: A Indústria Naval Civil e Militar na China e no Brasil (1950-2015). Dissertação. PPG-EEI, UFRGS: Porto Alegre, RS.

CEED (2014). Conferência "Defesa e Recursos Naturais" da UNASUL. Centro de Estudos Estratégicos de Defesa, Conselho Sul-Americano de Defesa. <http:// www.ceedcds.org.ar/Portugues/O4-EventosPort/o032-Eventos.html>

Cepik, M. (2005). Segurança na América do Sul: Traços Estruturais e Dinâmica Conjuntural. Observatório Político Sul-Americano, OPSA, IUPERJ/UCAM. Rio de Janeiro, RJ.

Cepik, M. (2008). A Crise Andina e o Futuro da UNASUL. Análise de Conjuntura OPSA, $n^{\circ} 4$, abril/2008, Observatório Político Sul-Americano (OPSA), IUPERJ/ UCAM.

Cepik, M. (2010). Combate ao terrorismo e Estado no Brasil: avaliação crítica e sugestões preliminares. p. 121-145. In: Herz, Monica; Amaral, Arthur. (2010) [orgs]. Terrorismo e Relações Internacionais: perspectivas para o século XXI. Ed. Puc/Loyola: Rio de Janeiro, RJ.

Cepik, M. (2014). La politique de défense bré-silienne: institutions, doctrine, capacités et économie. Foundation pour la Recherche Stratégique, 02/04/2014, Note $\mathrm{n}^{\circ} \quad$ 05/2014. <https://www.frstrategie.org/barreFRS/publications/ notes/2014/201405.pdf $>$

CERA (2006). Peak Oil Theory - World Running Out of Oil Soon - Is Faulty; Could Distort Policy \& Energy Debate. CERA Press Release, 14/11/2006. Cambridge Energy Research Associates, CERA: Londres, Reino Unido.

Chandler, A. (1994). Scale and scope: the dynamics of industrial capitalism. Harvard University Press: Massachusetts, EUA.

Chang, H. J. (2003). Chutando a escada: estratégia do desenvolvimento em perspectiva histórica. Editora UNESP: São Paulo, SP.

Chang, H. J. (2009). Maus Samaritanos: O mito do livre comércio e a história secreta do capitalismo. Editora Campus: Rio de Janeiro, RJ.

Chossudovsky, M. (2008). La desestabilización de Bolivia y la "Opción Kosovo". Global Research, 23/09/2008, Canadá. <http://www.globalresearch.ca/index. php?context $=$ va\&aid $=10315>$

CIRM (2010). Resolução n. 3/2010 da Comissão Interministerial para os Recursos do $\operatorname{Mar}($ CIRM). Estabelece o direito do Brasil em avaliar previamente pedidos de 
autorização para realização de pesquisas na Plataforma Continental além das 200 milhas náuticas. Comissão Interministerial para os Recursos do Mar, 26 de agosto de 2010. Secretaria da Comissão Interministerial para os Recursos do Mar. Governo Federal. Brasília, DF.

Conant, M. A. \& Gold, F. R. (1981). A geopolítica energética. Bibliex: Rio de Janeiro, RJ.

Corbett, J. (1999). Some Principles of Maritime Strategy. p. 149-263. In: Jablonsky, David (1999) [org.]. Roots of Strategy. Stackpole Books: Mechanicsburg.

Corrêa, F. G. (2010). O Projeto do Submarino Nuclear Brasileiro: uma história de ciência, tecnologia e soberania. Ed. Capax Dei: Rio de Janeiro, RJ.

Costa Braga, C. (2004). A Guerra da Lagosta. Serviço de Documentação da Marinha: Rio de Janeiro, RJ.

Coutinho Marcial, E. (2012). Construção de Cenários Prospectivos: Qual o melhor método? Revista do Centro de Estudos Estratégicos do Exército. Editorial 2012. p. 1-7.<www.eme.eb.mil.br/ceeex/public/arquivos/nep2012/ ConstrucaodeCenariosProspectivo_Artigo_EXERCITO_v3-1.pdf>

Coutinho Marcial, E. \& Santos Grumbach, R. J. (2002). Cenários Prospectivos: como construir um futuro melhor. FGV: Rio de Janeiro, RJ.

Dall'Onder Sebben, F. (2007). Separatismo e Hipótese de Guerra Local na Bolívia: Possíveis Implicações para o Brasil. Monografia, UFRGS: Porto Alegre, RS.

Dall'Onder Sebben, F. (2010). Bolívia: Logística Nacional e Construção do Estado. Dissertação de Mestrado em Ciência Política, UFRGS. Porto Alegre, RS. p. 50-92. <http://www.lume.ufrgs.br/bitstream/handle/10183/25487/000749341.pdf>

Dall'Onder Sebben, F. (2014). A Fronteira Brasil-Bolívia, o Separatismo e a Iniciativa das Casas da União. p. 65-80. In: Graça Hahn, M.; Quedi Martins, J. M. \& Kerr Oliveira, L. (2014). Casas de União: Políticas Públicas e Regiões de Fronteira. Instituto Sul-Americano de Política e Estratégia, ISAPE. Porto Alegre, RS.

De Conti Pagliari, G. (2009). O Brasil e a segurança na América do Sul. Ed. Juruá: Curitiba, PR.

Danilevicz Pereira, A. (2013). O Atlântico Sul, a África Austral e o Brasil: cooperação e desenvolvimento. Austral: Revista de Estratégia e Relações Internacionais, vol. 2, nº 04, p. 33-47, Jul-Dez/2013. 
Diallo Mamadou, A.; Fernandes, L. N.; Garcia, M. L. A. (2011). Conflito na Líbia: uma análise crítica do intervencionismo ocidental pelo poder e recursos energéticos em nome da defesa da democracia. IV Seminário Nacional de Ciência Política da UFRGS.

Estadão (2009). Regras do Pré-Sal ampliam poder do Estado na Exploração do Petróleo. O Estado de S. Paulo, 01/09/2009.

Fernandes More, R. (2012). Quando cangurus voarem: a declaração unilateral brasileira sobre direito de pesquisa além dos limites da plataforma continental - 2010. Revista de Direito Internacional, v. 9, n. 1, p. 61-68, jan./jun. 2012. Brasília, DF.

Fiori, J. L. (2009). O poder global e a nova geopolítica das nações. Crítica y Emancipación Revistalatinoamericana de ciencias sociales, Año I, no 2, p. 157-183. Primer Semestre/2009. <bibliotecavirtual.clacso.org.ar/ar/libros/secret/CyE/ CyE2/06opo.pdf>

Freedman, L. (2003). As duas primeiras gerações de estrategistas nucleares. In: Paret, Peter (2003) [org]. Construtores da estratégia moderna: de Maquiavel à Era Nuclear. tomo 2.Biblioteca do Exército: Rio de Janeiro, RJ.

Friedman, G. (2009). Os Próximos 100 Anos. . Ed. Best Business: Rio de Janeiro, RJ.

Friedman, G. (2012). Um Hemisfério Seguro. p. 231-252. In: FRIEDMAN, G. (2012). A Próxima Década. Ed. Novo Conceito: Ribeirão Preto, SP.

Fuser, I. (2007). O petróleo do Golfo Pérsico, ponto-chave da estratégia global dos Estados Unidos. p. 87-102. In: FRATI, Mila (2007) [org.]. Curso de formação em política internacional. Ed. Fundação Perseu Abramo: São Paulo, SP.

Fuser, I. (2008). Petróleo e Poder: o envolvimento militar dos Estados Unidos no Golfo Pérsico. Ed. Unesp: São Paulo, SP.

Fuser, I. (2013). Energia e Relações Internacionais. Ed. Saraiva: São Paulo, SP

García-Perez, J. (2005). Conflictos Territoriales e Luchas Fronterizas en América Latina durante los siglos XIX e XX. Norba Revista de História, vol. 18, p 215-241. México.

Gilpin, R. (1981). War and Change in International Politics. Cambridge. University Press: Cambridge, Inglaterra.

Googlemaps (2017). Updated extended continental shelf areas. UNCLOS \& GRID Arendal, Continental Shelf Programme. Mapa do GoogleMaps com dados da Comissão de Limites da Plataforma Continental da ONU (Commission on the 
Limits of the Continental Shelf, CLCS) e do programa GRID-Arendal, disponível em: < http://www.continentalshelf.org/visualize.aspx $>$

Graça Hahn, M. (2006). Tribunal Sul-Americano: Uma Concepção Cibernética de Integração. 2006. Dissertação de Mestrado, PPG-RI. IFCH, UFRGS: Porto Alegre, RS.

Graça Hahn, M.; Quedi Martins, J. M. \& Kerr Oliveira, L. (2014). Casas de União: Políticas Públicas e Regiões de Fronteira. Instituto Sul-Americano de Política e Estratégia, ISAPE. Porto Alegre, RS.

Graça Hahn, M.; Quedi Martins, J. M. \& Kerr Oliveira, L. (2014). Casas de União: Políticas Públicas e Regiões de Fronteira. Instituto Sul-Americano de Política e Estratégia, ISAPE. Porto Alegre, RS.

IBGE (2011). Atlas geográfico das zonas costeiras e oceânicas do Brasil. IBGE, Diretoria de Geociências. Rio de Janeiro, rj.

Jimenez,F.(2013). Cobaltfaz novas descobertasemLontrae Mavinga, nopré-salde Angola, em parceria com a Sonangol, BP - British Petroleum, Nazaki e Alper. PreSalt.com, 06 de Novembro de 2013. <www.presalt.com/pt/a-petrobras-e-o-pre-sal/362-portugues/africa-pre-sal/angola-pre-sal/2499-cobalt-faz-novas-descobertas-em-lontra-e-mavinga-no-pre-sal-de-angola-em-parceria-com-a-sonangol-bp-british-petroleum-nazaki-e-alper.html>

Kerr Oliveira, L. (2012). Energia como recurso de poder na política internacional: geopolítica, estratégia e o papel do Centro de Decisão Energética. Tese de Doutorado em Ciência Política. UFRGS: Porto Alegre, RS.

Kerr Oliveira, L. (2014). A Questão das Fronteiras diante dos Desafios das Transformações Tecnológicas e da Formação de Blocos Regionais. p. 81-114 In: Graça Hahn, M.; Quedi Martins, J. M. \& Kerr Oliveira, L. (2014). Casas de União: Políticas Públicas e Regiões de Fronteira. Instituto Sul-Americano de Política e Estratégia, ISAPE. Porto Alegre, RS.

Kerr Oliveira, L. \& Pautasso, Diego (2008). A segurança energética da China e as reações dos EUA. Revista Contexto Internacional. vol 30, $\mathrm{n}^{\circ}$ 2, dezembro de 2008.

Kerr Oliveira, L.; Brites, P. V. \& Cepik, M. A. C. (2014). O Pré-Sal e a Segurança do Atlântico Sul: a Defesa em Camadas e o papel da Integração Sul-Americana. Revista da Escola de Guerra Naval, v. 20, n 1 p. 139-164.

Kerr Oliveira, L.; Pereira Brites, P. V. \& Silva, Reis, J. A. (2013). A guerra proxy na Síria e as disputas estratégicas russo-estadunidenses no Oriente Médio. 
Boletim Mundorama, 20/09/2013, Boletim $n^{\circ}$ 99. <https://www.mundorama. net $/$ p $=11595>$

Klare, M. T. (2001). The new Geography of Conflict. Foreign Affairs, vol. 80, $\mathrm{n}^{\circ}$ 6, p.49-61. mai-jun/2001.

Klare, M. T. (2003). Guerras por los Recursos: El futuro escenario del conflicto global. Ed. Urano, Barcelona, Espanha.

Klare, M. T. (2006). Sangue por petróleo: a estratégia energética de Bush e Cheney. p. 201-223. In: Leys, C. \& Panitch, L. [orgs]. O novo desafio Imperial. Clacso, 2006.

Klare, M. T. (2008). Energy Security . p. 483-496. In: Williams, Paul D. (2008). Security Studies: An Introduction ${ }^{\circ}$ Ed. Routledge, Nova Iorque, EUA.

Landim, R. (2010). Petrobrás se expande em várias áreas e já movimenta 10\% do PIB. Valor de mercado da empresa cresceu 10 vezes, de US $\$ 18$ bi em janeiro de 2002 para US $\$ 200$ bi em dezembro de 2009. O Estado de S.Paulo, 30/01/2010. $<$ www.estadao.com.br/noticias/geral,petrobras-se-expande-em-varias-areas-e-ja-movimenta-10-do-pib,504139>

LEPLAC (sd). Plano de Levantamento da Plataforma Continental Brasileira (LEPLAC). Marinha do Brasil. < https://www.mar.mil.br/dhn/dhn/ass_leplac. $\underline{\mathrm{html}>}$

Lessa, A. C. (1999). A Guerra da Lagosta e outras guerras: conflito e cooperação nas relações França-Brasil (1960-1964). Cena Internacional, v. 1, p. 110- 120. UnB, Brasília, DF.

Maersk Oil (2013). Rift Asymmetry in the Equatorial Atlantic. Third Annual PaleoGIS E̊ PaleoClimate Users Conference, 23/12/2013. Slide de apresentação realizada por David Lewis/Maersk Oil. < <https://www.slideshare.net/TheRothwellGroup/ david-lewis-maersk2013-paleogis-users-conference-presentation>

Mahan, A. T. (1890). The Influence of Sea Power upon History, 1660-1783. [e-book]. Dodo Press.

Mares, David R. (1995). La Guerra Fria en los Conflictos Latinoamericanos: Mitos y Realidades. FASOC, año X, nº 2, p. 18-25. Santiago, Chile.

Marinha do Brasil (2017). A Plataforma Continental. Plano de Levantamento da Plataforma Continental Brasileira (LEPLAC). Secretaria da Comissão Interministerial para os Recursos do Mar, Marinha do Brasil. $<$ https://www.mar. mil.br/secirm/portugues/leplac.html> 
Mattar Nasser, R. \& Fracalossi Moraes, R. (2014). [orgs]. O Brasil e a segurança no seu entorno estratégico: América do Sul e Atlântico Sul. Ed. IPEA.: Brasília, DF.

Mearsheimer, J. J. (2001). The Tragedy of Great Power Politics. W. W. Norton: Nova Iorque, EUA; Londres: Reino Unido.

Mercopress (2015). Falklands/Malvinas: Argentina asks why UK is not punished for not complying with $\mathrm{Un}^{\circ}$ Mercopress, 24/07/2015. < $\underline{\text { http://en.mercopress. }}$ com/2015/07/24/falklands-malvinas-argentina-asks-why-uk-is-not-punished-for-not-complying-with-un $>$

Messias Costa, W. (2009). O Brasil e a América do Sul: cenários geopolíticos e os desafios da integração. Confins, n 7, 31 Outubro/2009.

Mitre, A. (2010). Das cinzas da ideologia: sistema regional, fronteiras e conflitos interestatais na América Latina. Plataforma Democrática, Working Paper nº 2, julho/2010.

Modelski, G. \& Thompson, W., R. (1989). Long Cycles and Global War. p. 23-54. In: Midlarsky, Manus I. (1989) [org.] Handbook of War Studies. Unwin Hyman, Boston.

Moniz Bandeira, L. A. (2008). O Brasil como potência regional e a importância estratégica da América do Sul na sua política exterior. Revista Espaço Acadêmico, $n^{\circ}$ 91, dezembro de 2008.

Moniz Bandeira, L. A. (2012). Guerra das Malvinas: petróleo e geopolítica. Revista Espaço Acadêmico, v. 11, n 132, p. 157-165.

Moniz Bandeira, L. A. (2013). A Segunda Guerra Fria: geopolítica e dimensão estratégica dos Estados Unidos : Das rebeliões na Eurásia à África do Norte e ao Oriente Médio. Ed. Civilização Brasileira: Rio de Janeiro, RJ.

OPEP (2016). World Oil Outlook. OPEC Secretariat. Organization Petroleum Exports Coutries, OPEC. Organização dos Países Exportadores de Petróleo. Viena, Áustria. <http://www.opec.org/opec_web/static_files_project/media/ downloads/publications/WOO\%202016.pdf>

Pamplona, V. (2012). Malvinas: apoio brasileiro à Argentina é antigo, diz governo. Veja.com. 29/01/2012. <http://veja.abril.com.br/noticia/mundo/malvinas-apoio-brasileiro-a-argentina-e-antigo-diz-governo/>

Pautasso, D. (2009). Os desdobramentos internacionais do desenvolvimento da demanda por petróleo na China. Meridiano 47, vol. 10, nº 109, agosto/2009. 
Pautasso, D. (2011). A economia continental chinesa e seu efeito gravitacional. Revista de Sociologia Política, vol. 19, suppl. 1, p. 45-56.

Pereira Silva, A. (2013). O novo pleito brasileiro no mar: a plataforma continental estendida e o Projeto Amazônia Azul. Revista Brasileira de Política Internacional, vol. $56, \mathrm{n}^{\circ} 1$, p.104-121.

Petrobrás (2017). Nossas Bacias Produtoras Marítimas e Terrestres. Bacias. Seção Principais Operações, da página Nossas Atividades. Portal da Petrobrás. Cartograma disponível online. Último acesso em janeiro de 2017. $<\underline{\text { www.petro- }}$ bras.com.br/pt/nossas-atividades/principais-operacoes/bacias/>

Piccolli, L. Machado, L \& Monteiro, V. F. (2016). A Guerra Híbrida e o papel da Rússia no conflito Sírio. Revista Brasileira de Estudos de Defesa, v. 3, n. 1, jan.-jun./2016, p. 189-203.

Pinheiro Guimarães, S. (2006). Desafios Brasileiros na Era dos Gigantes. Ed. Contraponto: Rio de Janeiro, RJ.

Pinheiro Guimarães, S. (2007). O mundo multipolar e a integração sul-americana. Revista Comunicação \&̊ Política, v. 25, nº 3, p. 169-189

Quartim Moraes, J. (2000). A esquerda militar no Brasil. Ed. Expressão Popular: São Paulo, SP.

Quedi Martins, J. M. (2008). Digitalização e guerra local: como fatores do equilíbrio internacional. Tese de Doutorado em Ciência Política. UFRGS: Porto Alegre, RS.

Rapoport, M. \& Laufer, R. (2000). Os Estados Unidos diante do Brasil e da Argentina: os golpes militares da década de 1960. Revista Brasileira de Política Internacional, v. $43, \mathrm{n}^{\circ}$ 1, p. 69-98.

Rasler, K. \& Thompson, W. R. (2005). Global War and the Political Economy os Structural Change. p. 301-331. In: MIDLARSKY, Manus I. (2005) [org.]. Handbook of War Studies II. $4^{\mathrm{a}}$ ed. The University of Michgan Press.

RT (2015). British firms discover oil and gas off Falklands, Argentina threatens legal action $^{\circ}$ RT, 02/04/2015. < https://www.rt.com/uk/246369-oil-gas-falkland-islands/>

Santos Xavier, A. T. (2009). África e a Geopolítica do Petróleo: Nigéria um ator estratégico. Revista Eletrônica Boletim do Tempo, Ano 4, Nº10, Rio de Janeiro, RJ.

Santos, R. M. R. (2009). A importância da guerra das Malvinas na consolidação da integração latino-americana nos anos 80. Revista Eletrônica Tempo Presente, Ano 4, $\mathrm{n}^{\circ} 16$. Rio de Janeiro, RJ. 
Schwartz, P. (2004). A Arte da Visão de Longo Prazo: Planejando o futuro em um mundo de incertezas. Ed. Best Seller: São Paulo, SP.

Shah, S. (2007). A História do Petróleo. L\&PM Editores: Porto Alegre, RS.

Silva Souza, I. D. S.; Passarini Takahashi, V. P. (2012). A visão de futuro por meio de cenários prospectivos: uma ferramenta para a antecipação da inovação disruptiva. Future Studies Research Journal: Trends and Strategies, v. 4, n 2, p. 102-132.

Soares Lima, M. R.; Hurrell, A. \& Narlikar, A. et al (2009) [orgs.]. Os BRICs e a Ordem Global. Ed. FGV: Rio de Janeiro, RJ.

Souza, J. M. (1999). Mar territorial, zona econômica exclusiva ou plataforma continental?. Revista Brasileira de Geofísica, vol. 17, $\mathrm{n}^{\circ}$ 1, p. 79-82.

Toni, J. (2006). Cenários e Análise Estratégica : questões metodológicas. Revista Espaço Acadêmico, ${ }^{\circ}$ 59, abril/2006.

UNASUL (2008). Estatuto do Conselho de Defesa Sul-Americano da UNASUL. Conselho de Defesa Sul-Americano. Santiago <http://www.ceedcds.org.ar/ Portugues/09-Downloads/PORT-ESTATUTO CDS.pdf>

UNDP \& WHO (2009). The Energy Access Situation in Developing Countries: A Review Focusing on the Least Developed Countries and Sub-Saharan Africa. United Nations Development Programme \& World Health Organization. $<$ http://content.undp.org/go/cms-service/stream/asset/? asset $\underline{\mathrm{id}=2205620}>$

US-EIA (2011). Annual Energy Outlook 2011 with Projections to 2035. Office of Integrated and International Energy Analysis. U.S. Department of Energy. Washington, DC.

US-EIA (2016). EIA projects 48\% increase in world energy consumption by 2040. Energy Information Agency, 12/05/2016. U.S. Department of Energy. Washington, DC. $<\underline{\text { https:// www.eia.gov/todayinenergy/detail.php?id=26212 }>}$

Victoriano Serrano, F. (2010). Estado, golpes de Estado y militarización en América Latina: una reflexión histórico política. Argumentos, vol. 23, n. 64, septiembre-diciembre/2010, p. 175-193. Universidad Autónoma Metropolitana Xochimilco, Distrito Federal, México.

Vigevani, T. (1999). Ciclos longos e cenários contemporâneos da sociedade internacional. Lua Nova: Revista de Cultura e Política, n.46, p. 5-53. 
Visentini, P. G. F. (2010). O Brasil, a América do Sul e a América Latina/Caribe. Oportunidades e desafios da integração. Fev/2010. Ed. Flacso: Buenos Aires, Argentina.

Visentini, P. G. F. (2013) [org.]. BRICS: as potências emergentes: China, Rússia, Índia, Brasil e África do Sul. Ed. Vozes: Petrópolis, RJ.

Vizentini, P. G. F. (2003). América do Sul, Espaço Geopolítico Prioritário do Projeto Nacional Brasileiro. p. 183-211. In: Rebelo, Aldo; Fernandes, Luis; Cardim, Henrique (2003). [orgs.]. Política externa do Brasil para o século XXI. Câmara dos Deputados: Brasília, DF.

Vizentini, P. G. F. (2008). O Brasil, o MERCOSUL e a integração na América do Sul. p. 93-129. In: Wiesebron, M.; Griffiths, M. (2008) [orgs.]. Processos de Integração regional e cooperação intercontinental desde 1989. Editora UFRGS: Porto Alegre, RS.

Vizentini, P. G. F. \& Wiesebron, M. (2006) [orgs]. Neo-hegemonia americana ou multipolaridade? Pólos de poder e sistema internacional. Ed. UFRGS: Porto Alegre, RS.

Wiesebron, M. (2013). Amazônia Azul: Pensando a Defesa do Território Marítimo Brasileiro. Austral: Revista Brasileira de Estratégia e Relações Internacionais v. 2, $\mathrm{n}^{\circ} 3$. Jan-Jun./2013.

Xavier Ferolla, S. \& Metri, P. (2006). Nem todo o petróleo é nosso. Ed. Paz \& Terra: São Paulo, SP.

Xavier Ferolla, S. \& Metri, P. (2008). Incertezas e cobiça sobre o petróleo do Brasil. Le Monde Diplomatique Brasil, 27/07/2008. < $\underline{\text { http://diplo.uol.com. }}$ $\underline{\mathrm{br} / 2008-07, \mathrm{a} 2511>}$

Yergin, D. (1992). O Petróleo: uma história de ganância, dinheiro e poder. Ed. Página Aberta: São Paulo, SP.

Yergin, D. (2006). Ensuring Energy Security. Foreign Affairs, vol. 85, n² 2, March/ April 2006. 


\section{NOTAS}

1. Para maiores detalhes sobre a perspectiva de análise de longa duração, ver: Braudel (1982, p. 7-39; 1992, p. 41-78) e Vigevani (1999).

2. Para situar os requisitos e procedimentos metodológicos envolvidos na construção de cenários, ver: Vigevani (1999); Coutinho Marcial \& Santos Grumbach (2002); Schwartz (2004); Toni (2006); Coutinho Marcial (2012); Silva Souza \& Passarini Takahashi (2012). 


\section{ANÁLISE DE ESTRUTURAS GEOPOLIITICAS E DE TENDÊNCIAS DE AUMENTO \\ DA COMPETIÇÃO INTERESTATAL INTERNACIONAL: \\ CONTRIBUIÇṌES PARA A PROSPECÇÃO DE CENÁRIOS DE AMEAÇAS À SOBERANIA BRASILEIRA SOBRE O PRÉ-SAL}

\section{RESUMO}

O objetivo deste artigo é, a partir da análise de condições e estruturas geopolíticas estratégicas de longo prazo, identificar os principais desafios para o Brasil exercer sua soberania sobre as reservas petrolíferas do pré-sal. A partir da análise das tendências geopolíticas elencadas, espera-se identificar variáveis e elementos para a construção de cenários de ameaças envolvendo o pré-sal.

Palavras-chave: Brasil; Pré-sal; Geopolítica; Cenários.

\section{ABSTRACT}

The purpose of this article is to identify the main challenges for Brazil to exercise its sovereignty over the oil reserves of the Pre-Salt, based on the analysis of long-term strategic geopolitical conditions and structures. From the analysis of geopolitical trends, it is expected to identify variables and elements for the construction of threat scenarios involving the pre-salt.

Keywords: Brazil; Pre-salt; Geopolitics; Scenarios. 